\title{
Protocol
}

\section{Preparation of Rough Microsomes from Rat Liver}

\author{
David D. Sabatini ${ }^{1}$ \\ Department of Cell Biology, NYU Medical School, New York, New York 10016
}

This protocol describes how to prepare rat liver rough microsomes that contain undegraded membrane-bound polysomes and can function very well in an in vitro translation system. It uses endogenous ribonuclease inhibitor in all steps, avoiding pelleting rough microsomes in all steps and sacrificing good recovery.

\section{MATERIALS}

It is essential that you consult the appropriate Material Safety Data Sheets and your institution's Environmental Health and Safety Office for proper handling of equipment and hazardous materials used in this protocol.

RECIPES: Please see the end of this protocol for recipes indicated by $<R>$. Additional recipes can be found online at http://cshprotocols.cshlp.org/site/recipes.

\section{Reagents}

Dithiothreitol (DTT)

DOC (sodium deoxycholate)

Hog pancreas $\alpha$-amylase (optional; see Step 1)

Homogenizing medium $(\mathrm{HM})<\mathrm{R}>$

For general considerations on the choice of homogenizing medium and its ionic composition, see Discussion.

Rats (Sprague-Dawley males)

The number of rats depends on the amount of rough microsomes to be prepared. Because the liver from one 150 -g rat ( $6 \mathrm{~g}$ ) contains $\sim 10 \mathrm{mg}$ of rough microsomes per gram of liver as protein (Adelman et al. 1974), the number of rats can be estimated assuming the recovery is 50\%. Additionally, a maximum amount of liver tissue that can be processed is limited by the capacity of the Beckman Ti60 rotor, which holds eight 25- $\mathrm{mL}$ ultracentrifuge tubes. Approximately $13 \mathrm{~mL}$ of the postmitochondrial supernatant (PMS) is required to prepare each one-step gradient (see Steps 11 and 12); therefore, $105 \mathrm{~mL}$ of PMS is required to prepare eight gradients. This volume of PMS is usually obtained from $\sim 25 \mathrm{~g}$ of livers (four or five 150-g male starved rats). Additionally, 50-60 g of livers are typically required to prepare high-speed supernatants (HSSs; see Step 15). See Discussion.

RNase-IN (optional; see Step 21 and Discussion)

Sucrose $(2.5 \mathrm{M})$

Check the density of the $2.5 \mathrm{~m}$ sucrose with an Abbe 3-L refractometer (Milton Roy). After confirming the density, pass the solution through a 1.2- $\mu \mathrm{m}$ membrane filter and store at $4^{\circ} \mathrm{C}$.

Sucrose has been most frequently used as the gradient medium for preparing microsomes, although it is highly viscous at high concentrations, particularly at a temperature lower than $5^{\circ} \mathrm{C}$. Other types of gradient media are

\footnotetext{
${ }^{1}$ Correspondence: david.sabatini@nyumc.org

(C) 2014 Cold Spring Harbor Laboratory Press

Cite this protocol as Cold Spring Harb Protoc; doi:10.1101/pdb.prot079970
} 
D.D. Sabatini

available, including Ficoll, Percoll, Metrizamide, Nycodenz, and Metrizoate. Although these may be used for analytical purposes, they are not routinely used for preparations of microsomes in which functional integrity must be maintained. Large amounts of media such as Nycodenz are expensive, and microsome behavior may be unpredictable in this medium (Graham et al. 1990).

Sucrose $(0.25 \mathrm{M}) / \mathrm{DTT}$ ( $3 \mathrm{~mm}$ ) prepared in water or TKM buffer

TK20M buffer for rough microsomes $<\mathrm{R}>$

TKM buffer for rough microsomes $<\mathrm{R}>$

Triton X-100

Equipment

Beakers

Cheesecloth (Grade 60; American Fiber and Finishing Inc.)

Dounce homogenizer $(40 \mathrm{~mL}$ ) with two pestles (Wheaton size A: 0.001-0.003 inch, normal clearance, and size B: $0.0025-0.035$ inch, loose fitting) or a Potter-Elvehjem glass/Teflon homogenizer (0.040.06 inch clearance; Kontes) with a motor-driven Teflon pestle

Gel filtration column (G100) (optional; see Step 15)

Glass plate (see Step 4)

Graduated cylinder

Kimwipes

Membrane filters (1.2- $\mu \mathrm{m}$; Millipore)

Metal cannula

Parafilm

Razor blades

Refrigerated centrifuge (Sorvall), SS34 rotor, and appropriate tubes

Surgical tools

Syringe

Ultracentrifuge (Beckman Instruments), SW41 and Ti60 rotors, and appropriate tubes

\section{Collection of Fresh Liver}

1. Sacrifice an appropriate number of $\sim 150$-g male rats (Sprague-Dawley) by cervical dislocation and decapitation.

2. After draining the blood, open the abdominal and thoracic cavities, excise the livers, and place them into a beaker containing cold HM.

This and all remaining steps must be performed in the cold room $\left(\sim 4^{\circ} \mathrm{C}\right)$.

3. Wash the livers with cold HM, place them on a paper towel, remove connective tissues (if any), and rapidly weigh them.

4. Place the livers on a clean glass plate and mince them as small as possible with a razor blade until a paste-like consistency forms.

Alternatively, chop the livers with scissors in a small beaker without HM (HM hinders the process).

5. Place the minced livers in a beaker containing $4-5$ volumes of cold HM, swirl gently, and allow the pieces to settle to the bottom before decanting the liquid to remove some blood (see Discussion).

Use this minced liver to prepare a rough microsome fraction as described in Steps 6-14 or to prepare HSSs as described in Steps 15-19. 


\section{Preparation of a Rough Microsome Fraction}

6. Homogenize the minced livers in 4 volumes of HM in either a loose-fitting Dounce homogenizer with 5-10 gentle strokes (once up and down is one stroke) or in a Potter-Elvehjem glass/Teflon homogenizer with a motor-driven Teflon pestle at $\sim 1700 \mathrm{rev} / \mathrm{min}$ (5-10 strokes), keeping the homogenizer in ice water.

When a Potter-Elvehjem Teflon homogenizer is used, the pestle tip should reach the bottom on the first down stroke. If it is difficult to reach the bottom because of large pieces of tissue, try to move the tip down to the bottom by continuous up and down movements of the pestle with a narrow amplitude. Once the tip reaches the bottom, it will move downward smoothly thereafter. Otherwise, many pieces may be left unhomogenized. Do not use quick up and down movements, as this may cause foaming. Do not splash the tissue suspension or homogenate by pushing the pestle down into the tissue suspension or homogenate from air in a rapid or strong motion. Instead, slide the pestle down slowly until the tip reaches the surface of the tissue suspension or homogenate and then push it down to the bottom.

Starting at this step, it is important to measure the volume of each fraction and save an aliquot for chemical analysis.

7. Filter the homogenate into a graduated cylinder through four to six layers of cheesecloth premoistened with HM. At the end of filtration, close the cheesecloth by bringing the edges together and squeezing the bag slowly from the mouth to the bottom.

8. Raise the homogenate volume to five times the liver weight (i.e., $20 \%[\mathrm{w} / \mathrm{v}]$ ) with $\mathrm{HM}$, cover with Parafilm, and invert the cylinder to mix the homogenate.

9. Centrifuge the homogenate at $2500 \mathrm{rpm}$ for $5 \mathrm{~min}$ at $4^{\circ} \mathrm{C}$ in appropriate tubes for an SS34 rotor in a Sorvall refrigerated centrifuge and then increase the speed to $15,000 \mathrm{rpm}(23,000 \mathrm{~g} \max )$ for $15 \mathrm{~min}$.

The centrifugation conditions should be decided according to the purpose of the preparation. When better recovery of membrane-bound ribosomes is important, centrifuge at $8000 \mathrm{rpm}$ (7500g max) for $10 \mathrm{~min}$, because mitochondrial contamination is acceptable in these preparations.

10. Remove any white layer on the surface by soaking it up with a Kimwipe or aspiration with a syringe and metal cannula, and then transfer the supernatant (postmitochondrial supernatant; PMS) into a graduated cylinder using a syringe and cannula.

11. Prepare three sucrose solutions using PMS and 2.5 м sucrose.

- PMS containing $1.35 \mathrm{~m}$ sucrose (prepared by mixing one volume of PMS with 0.7 volume of 2.5 м sucrose)

- PMS containing 1.55 M sucrose (prepared by mixing one volume of PMS with 1.1 volumes of 2.5 M sucrose)

- PMS containing $1.8 \mathrm{M}$ sucrose (prepared by mixing one volume of PMS with 2 volumes of $2.5 \mathrm{M}$ sucrose)

12. Prepare step gradients in ultracentrifuge tubes for a Ti60 rotor using the solutions prepared in Step 11. Layer the solutions from the bottom to the top starting with $5 \mathrm{~mL}$ of $1.8 \mathrm{M}$ sucrose-PMS, $3 \mathrm{~mL}$ of $1.55 \mathrm{~m}$ sucrose-PMS, $15-17 \mathrm{~mL}$ of $1.35 \mathrm{~m}$ sucrose-PMS, and finally 2$3 \mathrm{~mL}$ of $1 \mathrm{M}$ sucrose.

13. Centrifuge tubes at $48,000 \mathrm{rpm}(240,000 \mathrm{~g} \max )$ for at least $6 \mathrm{~h}$ in a Ti60 rotor in an ultracentrifuge at $4^{\circ} \mathrm{C}$.

14. Collect and pool the membranes that may have sedimented in two bands or as one diffuse band in the $1.55 \mathrm{~m}$ sucrose layer using a syringe and metal cannula.

This is defined as the rough microsome fraction. Occasionally, two bands can form: One at the interface between the $1.35 \mathrm{M}$ and $1.55 \mathrm{~m}$ sucrose layers (light rough microsomes) and the other at the interface between the $1.55 \mathrm{M}$ and $1.8 \mathrm{M}$ sucrose layers (heavy rough microsomes). Process the rough microsomal fraction as appropriate using one of the three procedures below (Steps 20-23, 24-26, or 27-28). 
D.D. Sabatini

\section{Preparation of HSSs}

15. Homogenize minced livers in 2 volumes of $0.25 \mathrm{~m}$ sucrose containing $3 \mathrm{~mm}$ DTT or TKM containing $0.25 \mathrm{~m}$ sucrose and $3 \mathrm{~mm}$ DTT. Use the homogenization conditions described as in Step 6.

The amount of liver to be used depends on how much HSS is needed. Generally 50-60 g are used.

16. Centrifuge the homogenate at $15,000 \mathrm{rpm}$ for $15 \mathrm{~min}$ in an SS34 rotor in a Sorvall refrigerated centrifuge, and remove and save the supernatant.

17. Centrifuge the supernatant at $45,000 \mathrm{rpm}(200,000 \mathrm{~g} \max )$ for $60 \mathrm{~min}$ in a Ti60 rotor in an ultracentrifuge at $4^{\circ} \mathrm{C}$.

18. Remove and discard the top lipid layer, and save four-fifths of the solution from the top as endogenous RNase inhibitor (HSS). Aliquot HSS and keep at $-70^{\circ} \mathrm{C}$.

19. If in vitro translation will be performed, use a G100 gel filtration column to prepare a G100 fraction from rat liver HSS (Gaetani et al. 1983).

Processing of the Rough Microsome Fraction

\section{Preparation of Membrane-Bound Polysomes}

20. Dilute the rough microsome fraction from Step 14 1:3 with TK20M containing HSS (20\% v/v), add Triton X-100 and DOC to final concentrations of $1 \%$ and $0.5 \%$, respectively, and allow the sample to stand on ice for $10 \mathrm{~min}$.

21. Prepare step gradients in tubes for a Ti60 rotor that contain (from the bottom to the top): $5 \mathrm{~mL}$ of TK20M containing $2.0 \mathrm{M}$ sucrose and either HSS (10\% v/v) or human placenta ribonuclease inhibitor (RNase-IN) (2-4 units $/ \mathrm{mL}$ ), $3 \mathrm{~mL}$ of TK20M containing $1.55 \mathrm{~m}$ sucrose and HSS $(10 \% \mathrm{v} / \mathrm{v})$, and $15-18 \mathrm{~mL}$ of the detergent-treated rough microsome fraction from Step 20.

22. Centrifuge the gradients at $44,000 \mathrm{rpm}(200,000 \mathrm{~g} \max )$ for $14-16 \mathrm{~h}$ at $4^{\circ} \mathrm{C}$ in an ultracentrifuge.

23. Remove the supernatant by decanting. Immediately wash the inside wall of the centrifuge tube with $3-5 \mathrm{~mL}$ of TKM (pouring the buffer on the wall, and not directly on the polyribosomal pellet, gently swirling and decanting the wash). Stand the tube on a clean paper towel upside down for several minutes, wipe the inside wall with a Kimwipe, and store at $-70^{\circ} \mathrm{C}$ until used.

Decant the supernatant or wash in one step. Do not stop during the decanting step to turn the tube to the right-side-up position because some of the surface of the pellet or the entire pellet, if it is small and soft, may loosen. When the tubes are placed on a paper towel upside down after decanting, do not leave the tubes unattended because pellets that are not tightly packed at the bottom of the tube may slide down along the tube wall.

When the supernatant including the detergent-treated sample, 1.55 м sucrose layer, and 2.0 m sucrose layer is removed, it is recommended to save the $2.0 \mathrm{~m}$ sucrose layer by pouring it into a different tube until a reasonable recovery of membrane-bound ribosomes is confirmed. This is because if the temperature in the centrifuge is not maintained at exactly $4^{\circ} \mathrm{C}$ and it drops to $2^{\circ} \mathrm{C}$ or $1^{\circ} \mathrm{C}$, many ribosomes may not sediment to the pellet and remain in the $2.0 \mathrm{~m}$ sucrose layer.

\section{Concentration of Rough Microsomes for In Vitro Translation}

24. Dilute the rough microsome fraction 1:4 with TKM containing HSS (10\% v/v). Layer $8 \mathrm{~mL}$ of the diluted fraction onto gradients made in tubes for an SW41 rotor that contain (from the bottom to the top) $1 \mathrm{~mL}$ of TKM containing $1.8 \mathrm{~m}$ sucrose and HSS (10\% v/v), $1 \mathrm{~mL}$ of TKM containing $1.3 \mathrm{~m}$ sucrose and the G100 fraction from Step $19(20 \% \mathrm{v} / \mathrm{v})$, and $2 \mathrm{~mL}$ of TKM containing $0.7 \mathrm{M}$ sucrose and HSS $(10 \% \mathrm{v} / \mathrm{v})$.

25. Centrifuge at $35,000 \mathrm{rpm}(210,000 \mathrm{~g} \max )$ in an $\mathrm{SW} 41$ rotor for $60 \mathrm{~min}$ at $4^{\circ} \mathrm{C}$ in an ultracentrifuge. 
26. Collect the band formed at the interface between the $1.8 \mathrm{M}$ and $1.3 \mathrm{~m}$ sucrose layers in as small a volume as possible using a syringe and metal cannula in order to avoid lowering microsome concentration, and use immediately for translation in a G100 system.

The method for in vitro translation of rough microsomes using the G100 fraction is described by Feldman et al. (1982) and Gaetani et al. (1983).

\section{Processing for Experiments That Do Not Require Intact Membrane-Bound Polysomes}

27. Dilute the rough microsome fraction 1:3 with TKM and centrifuge at 40,000 $\mathrm{rpm}(160,000 \mathrm{~g}$ max $)$ for $60 \mathrm{~min}$ in a Ti60 rotor at $4^{\circ} \mathrm{C}$ in an ultracentrifuge.

28. Remove the supernatant by decanting, stand the tubes on a clean paper towel for a few minutes, wipe the inside wall with a Kimwipe, and store at $-70^{\circ} \mathrm{C}$ until used.

Watch tubes to ensure a loose pellet does not slide down the wall.

Although frozen livers may be suitable for some applications (Fleischer and Kervina 1974), rough microsomes and membrane-bound ribosomes, which are active in in vitro translation, should always be prepared from fresh livers (Kruppa and Sabatini 1977; Feldman et al. 1982; Gaetani et al. 1983). Likewise, rough microsomes that are used for a protein translocation assay should be prepared from fresh organs as quickly as possible (Walter and Blobel 1983). Isolated rough microsomes can be kept at $-70^{\circ} \mathrm{C}$ without losing translocation ability if aliquoted and used within three freeze-and-thaw cycles.

Livers removed from animals contain significant amounts of blood. For most studies on synthesis, intracellular transport, and secretion of plasma proteins, the presence of blood during homogenization is a serious problem. The presence of blood also presents problems in studies on microsomal cytochromes because during normal homogenization procedures, erythrocytes are disrupted, resulting in the release of hemoglobin and membrane derivatives. Microsomes, which are negatively charged (Dallner 1974), readily adsorb hemoglobin. Treatment of minced livers as described in this procedure (Step 5) seems to be sufficient to remove blood.

Starvation of the animals for $16-18 \mathrm{~h}$ before killing decreases glycogen content to $\sim 1 \mathrm{mg} / \mathrm{g}$ wet weight of liver and also decreases liver weight by $\sim 30 \%$. This treatment increases glucose-6-phosphatase activity (Dallner 1974) and may cause changes in the distribution of free and membranebound polysomes (Staehelin et al. 1967; Yap et al. 1978). However, when unfasted rats are used, free ribosome and microsome fractions contain many glycogen granules, which cause some technical problems. In addition, the amount of rough and smooth microsomes obtained in the PMS (i.e., after the low-speed centrifugation in Step 9) increases by 30\%-40\% in unfasted rats (Dallner 1974). To avoid glycogen problems, homogenates from unfasted rats can be treated with hog pancreas $\alpha-$ amylase (Sigma-Aldrich) 10 units $/ \mathrm{mL}$ for $15 \mathrm{~min}$ at $4^{\circ} \mathrm{C}$ (Ramsey and Steele 1979). This incubation would normally be performed after Step 7 and before Step 8 in the protocol above.

The high-speed supernatant (HSS) obtained from rat liver contains potent RNase inhibitor activity (Blobel and Potter 1966), and rat liver rough microsomes contain RNase activity (Blobel and Potter 1966; Feldman et al. 1982; Gaetani et al. 1983). Therefore, the preparation of undegraded membranebound polysomes from rat livers must be performed in the presence of either endogenous or exogenously added RNase inhibitors. Because rat liver HSS contains potent inhibitory activity (10\% HSS can completely inhibit RNase activity present in $\sim 8 \mathrm{~A}_{280 \mathrm{~nm}}$ units of rough microsomes), some investigators have used the PMS as a source of the inhibitor to prepare sucrose gradient solutions (Feldman et al. 1982). However, it should be stressed here that the inhibitory activity is not effective with all tissues. For example, it cannot effectively inhibit RNase activity in mouse liver homogenate. Interestingly, microsomes from dog and pigeon pancreas and myeloma cells contain an undetectable amount of RNase. G100 fraction, which is prepared from HSS, also has a potent RNase inhibitory activity (Feldman et al. 1982). 
Generally, $0.25 \mathrm{M}-0.5 \mathrm{M}$ sucrose solutions are used for the homogenization medium. To isolate a relatively pure nuclear fraction by one-step centrifugation from the homogenate, some investigators (Adelman et al. 1974; Kruppa and Sabatini 1977) have used $1.0 \mathrm{~m}$ sucrose to raise the sucrose concentration of the homogenate without increasing the volume significantly. In this case, homogenization should be performed carefully so as not to increase the temperature of the homogenate due to frictional force. To avoid aggregation, tissues are homogenized in a sucrose solution without ions. Endogenous ions appear to be sufficient to maintain a physiological environment for microsomes as long as the tissues are homogenized in $20 \%(\mathrm{w} / \mathrm{v})$ or higher sucrose concentration. However, when microsomes are to be used for in vitro protein synthesis, $\mathrm{Mg}^{2+}$ ions should be added to the buffer for subfractionation. For quantitation of free and membrane-bound polysomes, $\mathrm{Mg}^{2+}$ ions should be included in the homogenizing medium. Microsomes should be suspended in a high sucrose concentration because microsomes are permeable to sucrose (Dallner 1974) and stable in higher sucrose concentrations (Depierre and Dallner 1976). However, in some instances, the high sucrose concentration should be avoided. For example, ATPase activity of rough microsomes (Depierre and Dallner 1974) and in vitro translation of rough microsomes in the G100 system (Gaetani et al. 1983) are inhibited by high sucrose concentrations.

Microsomes have a tendency to aggregate, even in the absence of cations. As described by Dallner (1974), this is true for both rough and smooth microsomes, although smooth microsomes are more sensitive and unstable. Protein stability as reflected by the preservation of enzyme activity requires either high protein concentration or high sucrose concentration. Therefore, the protein concentration should be $>5 \mathrm{mg} / \mathrm{mL}$ and the sucrose concentration should be $>0.25 \mathrm{M}$. If the protein concentration is lower, protecting colloids such as albumin, spermine, or spermidine should be added. Alternately, the sucrose concentration can be raised to $\sim 1 \mathrm{M}$. Pelleting as a method to concentrate the sample should be avoided, as an isolated microsomal fraction sediments badly and aggregates frequently. Instead, the microsomal suspension should be layered onto a 2- to $4-\mathrm{mL} 1.35 \mathrm{M}$ sucrose cushion for smooth microsomes, or $1.8 \mathrm{~m}$ sucrose cushion for rough microsomes, and centrifuged in a swinging-bucket rotor. The band formed on the cushion is collected after centrifugation at $\sim 100,000 \mathrm{~g}$ max for a short time (e.g., $30 \mathrm{~min}$ ) (this centrifugation condition depends on the sucrose concentration and volume of the microsome suspension).

This protocol is based on the combined procedures of Kruppa and Sabatini (1977) and Gaetani et al. (1983).

Homogenizing Medium

$0.5 \mathrm{M}$ sucrose

$1 \mathrm{~mm}$ dithiothreitol (DTT)

TK20M Buffer for Rough Microsomes

$50 \mathrm{~mm}$ Tris- $\mathrm{HCl}(\mathrm{pH} 7.5)$

$50 \mathrm{~mm} \mathrm{KCl}$

$20 \mathrm{mM} \mathrm{MgCl}_{2}$

TKM Buffer for Rough Microsomes

$50 \mathrm{~mm}$ Tris- $\mathrm{HCl}$ (pH 7.5)

$50 \mathrm{~mm} \mathrm{KCl}$

$5 \mathrm{mM} \mathrm{MgCl}_{2}$ 


\section{REFERENCES}

Adelman M, Blobel G, Sabatini DD. 1974. An improved cell fractionation procedure for the preparation of rat liver membrane-bound ribosomes. Methods Enzymol 31: 201-215.

Blobel G, Potter VA. 1966. Relation of ribonuclease and ribonuclease inhibitor to the isolation of polysomes from rat liver. Proc Natl Acad Sci 55: 1283-1288.

Dallner G. 1974. Isolation of rough and smooth microsomes-General. Methods Enzymol 31: 191-201.

Depierre J, Dallner G. 1976. Isolation, sub-fractionation and characterization of the endoplasmic reticulum. In Biochemical analysis of membranes (ed. Maddy AH), pp. 79-131. John Wiley, New York.

Feldman RA, Gaetani S, Morimoto T. 1982. Preparation of functional rough microsomes from WI-38 human diploid fibroblasts, HeLa cells and rat liver. In Cancer cell organelles (ed. Reid E, et al.), pp. 263-292. John Wiley, New York.

Fleischer S, Kervina M. 1974. Long-term preservation of liver for subcellular fractionation. Sub-cellular fraction of rat liver. Methods Enzymol 31: $1-41$

Gaetani S, Smith J, Feldman RA, Morimoto T. 1983. Preparation of rough microsomes and membrane-bound polysomes that are active in protein synthesis in vitro. Methods Enzymol 96: 3-24.
Graham JM, Ford T, Rickwood D. 1990. Isolation of the major subcellular organelles from mouse liver using Nycodenz gradients without the use of an ultracentrifuge. Anal Biochem 187: 318323.

Kruppa J, Sabatini DD. 1977. Release of poly A $^{+}$messenger RNA from rat liver rough microsomes upon disassembly of bound polysomes. J Cell Biol 74: 414-427.

Ramsey JC, Steele WJ. 1979. A method for visualizing and quantifying the total complement of free and membrane-bound ribosomes in rat liver. Anal Biochem 92: 105-119.

Staehelin T, Verney E, Sidransky H. 1967. The influence of nutritional change on polyribosomes of the liver. Biochim Biophys Acta 145: 105-119.

Walter P, Blobel G. 1983. Preparation of microsomal membranes for cotranslational protein translocation. Methods Enzymol 96: 84-93.

Yap SH, Strair RK, Shafritz DA. 1978. Identification of albumin mRNPs in the cytosol of fasting rat liver and influence of tryptophan or a mixture of amino acids. Biochem Biophys Res Commun 83: 427433. 


\section{Preparation of Rough Microsomes from Rat Liver}

David D. Sabatini

Cold Spring Harb Protoc; doi: 10.1101/pdb.prot079970

\begin{tabular}{cc}
\hline $\begin{array}{c}\text { Email Alerting } \\
\text { Service }\end{array}$ & Receive free email alerts when new articles cite this article - click here. \\
\hline $\begin{array}{c}\text { Subject } \\
\text { Categories }\end{array}$ & $\begin{array}{c}\text { Browse articles on similar topics from Cold Spring Harbor Protocols. } \\
\text { Cell Biology, general (1382 articles) } \\
\text { Preparation of Cellular and Subcellular Extracts (104 articles) } \\
\text { Subcellular Fractionation (88 articles) }\end{array}$ \\
\hline
\end{tabular}

